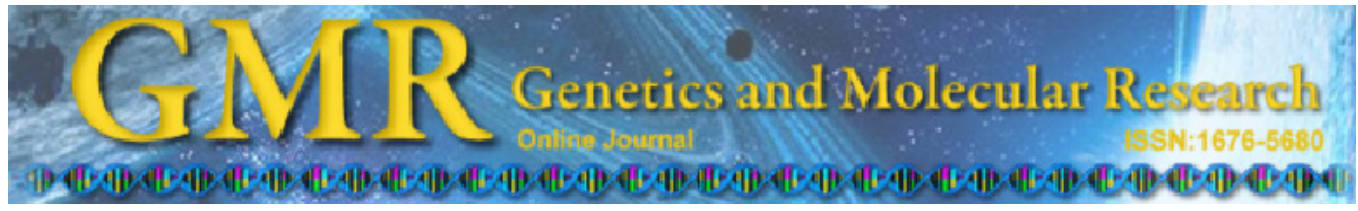

\title{
Expression of neurotrophin-4/5 in Streptococcus pneumoniae meningitis
}

\author{
H. Zhang' ${ }^{1}$ H.Y. Qian' ${ }^{2}$ and L. Li $^{3}$ \\ ${ }^{1}$ Department of Emergency Pediatrics, Liaocheng People's Hospital, \\ Shandong Province, Liaocheng, China \\ ${ }^{2}$ Department of Pediatrics, \\ Brain Hospital Affiliated to Liaocheng People's Hospital, Shandong Province, \\ Liaocheng, China \\ ${ }^{3}$ Department of Pediatrics, \\ Xinhua Hospital Affiliated to Shanghai Jiaotong University School of Medicine, \\ Shanghai, China
}

Corresponding author: L. Li

E-mail: linglicn@yeah.net

Genet. Mol. Res. 13 (2): 2994-3001 (2014)

Received June 5, 2013

Accepted October 25, 2013

Published April 16, 2014

DOI http://dx.doi.org/10.4238/2014.April.16.8

\begin{abstract}
This study aims to investigate the expression of neurotrophin-4/5 (NT-4/5) in the pallium and hippocampus in juvenile rats with intraventricular injection of Streptococcus pneumoniae. We used 40 SPF SD rats (3 weeks old, regardless of gender) in this study. We drew $50 \mu \mathrm{L}$ cerebrospinal fluid, and then, we injected $50 \mu \mathrm{L}$ normal saline and S. pneumoniae suspension $\left(10^{8} \mathrm{CFU} / \mathrm{mL}\right)$ in the brain pool (normal control group and infection group, respectively). After $24 \mathrm{~h}$, the cerebrospinal fluid was collected for bacterial culture and white blood cell count. The immunohistochemical staining was conducted at the day 1,2, and 5, and the expression of NT-4/5 in rat brain tissue was observed. Compared with the normal control group, NT-4/5 expression in the pallium and hippocampus of rats in the 24-h infection group was significantly increased (both $\mathrm{P}<0.05$ ). NT-4/5 expression in the pallium and hippocampus in the 5-day infection group was significantly
\end{abstract}


lower than that in the 24-h infection group $(\mathrm{P}<0.05)$, and they were significantly higher than the normal control group $(\mathrm{P}<0.05)$. After intraventricular injection of $S$. pneumoniae, the expression of NT-4/5 in the pallium and hippocampus in juvenile rats was increased, especially during early disease course.

Key words: Streptococcus pneumoniae; Neurotrophin-4/5; Juvenile rat; Pallium; Hippocampus

\section{INTRODUCTION}

Neurotrophin-4 (NT-4) is the fourth member of the nerve growth factor family (Ip et al., 1992; Fandl et al., 1994). NT-4/5 is the neuronal survival factor of the peripheral and central nervous systems, and its physiological role is very important (Hefti, 1997; Golz et al., 2006; Nikolaou et al., 2006; Chi and Powley, 2007; Chen et al., 2007; Chung et al., 2007; Engelhardt et al., 2007; Jabbar et al., 2007; Malamitsi-Puchner et al., 2007; Nakajima et al., 2007). Some experiments have confirmed that local injection of NT- $4 / 5$ regenerated the axonal quality of the injured nerve and the nerve function was significantly recovered (Yin et al., 2001). NT-4 can protect neuronal degeneration and can be used to treat peripheral motor neuron injury (Hefti, 1997). Studies suggest that NT-4/5 is widely distributed in the central nervous system, but its content is lower than those of a majority of other factors. Moreover, there is no great difference in the NT- $4 / 5$ content in various encephalic regions. NT- $4 / 5$ has two types of specific receptors: low-affinity p 75 receptor and high-affinity TrkB receptor (Thoenen, 1995). Among them, TrkB receptor is the specific signal transduction receptor of NT-4/5. NT-4/5 chiefly combines with the high-affinity receptor TrkB on the cytomembrane surface to play a role via the signal transduction mechanism. Similarly, it also combines with the low-affinity receptor p 75 . p75 receptor can enhance the discernment of Trk receptor ligand and play an important role in the antidromic conduction of neurotrophic factors (Xie et al., 2000).

The mortality and neurological sequelae associated with bacterial meningitis, especially Streptococcus pneumoniae meningitis, are very high (Golz et al., 2006; Chen et al., 2007; Engelhardt et al., 2007; Jabbar et al., 2007; Malamitsi-Puchner et al., 2007). The brain parenchymal damage due to bacterial meningitis will cause local sensorimotor disorders, epilepsy, mental retardation, and developmental retardation, and the cranial nerve damage can lead to deafness, blindness, and facial paralysis (Yin et al., 2001). The protective role of NT$4 / 5$ in cerebral injury is increasingly highlighted, but there is no report on its expression and role in the inflammatory tissues, especially in case of bacterial meningitis. This study is to observe changes in the characteristics of NT-4/5 expression in the pallium and hippocampus of the S. pneumoniae-induced cerebral injury model by establishing the acute $S$. pneumoniaeinfectious cerebral injury model of 3 -week-old rats by using immunohistochemical methods to investigate its neuroprotective effect.

\section{MATERIAL AND METHODS}

\section{Streptococcus pneumoniae suspension preparation}

Recovered type III S. pneumoniae strains were inoculated onto blood agar culture me- 
dium, incubated overnight in the environment of $5 \% \mathrm{CO}_{2}$ at $37^{\circ} \mathrm{C}$, transferred to VITAL AER broth, and incubated in the environment of $5 \% \mathrm{CO}_{2}$ at $37^{\circ} \mathrm{C}$ until logarithmic growth medium phase, centrifuged, and washed with normal saline twice. After the supernatant was removed, the remaining was diluted with normal saline to $10^{8} \mathrm{cfu} / \mathrm{mL}$.

\section{Induction of meningitis}

Experimental SPF-grade SD rats (3 weeks old, male or female) were provided by the Animal Research Institute of Kunming Medical University. Meningitis induction was performed according to the method provided by Diab et al. (1997). The rats were anesthetized with $0.15-0.3$ $\mathrm{mL} / 100 \mathrm{~g} \mathrm{10 \%}$ chloral hydrate by intraperitoneal injection and fixed onto the stereotaxic apparatus. Subsequently, cisternal puncture was conducted, and $50 \mu \mathrm{L}$ cerebrospinal fluid was taken from each rat. According to different experimental purposes, $S$. pneumoniae suspension $\left(10^{8} \mathrm{cfu} /\right.$ $\mathrm{mL})$ and normal saline $(50 \mu \mathrm{L})$ were injected. Subsequently, the rats were placed in cages at $23^{\circ} \mathrm{C}$ in a 12-h light/dark cycle, with free access to food and water. At $24 \mathrm{~h}$ after cisternal injection, $50 \mu \mathrm{L}$ cerebrospinal fluid was collected for bacterial culture and white blood cell count. Nerve function defect scoring was conducted for all experimental rats. Nerve function defect score was according to score criteria provided by Longa et al. (1989): 0 point, no obvious neurologic symptom; 1 point, not fully extend left forepaw; 2 points, rotate to left; 3 points, topple and fall to left as walking; 4 points, unable to walk independently and level of consciousness dropping. Accumulated score over 1 represented nerve function defect. This study was carried out in strict accordance with the recommendations in the Guide for the Care and Use of Laboratory Animals of the National Institutes of Health. The animal use protocol has been reviewed and approved by the Institutional Animal Care and Use Committee (IACUC) of the Liaocheng Hospital.

\section{Animal grouping and intervention}

A total of $40 \mathrm{SD}$ rats (3 weeks old) were randomly divided into 4 groups. For the normal control group $(\mathrm{N}=10)$, after $50 \mu \mathrm{L}$ cerebrospinal fluid was taken out from the rat brain cistern, $50 \mu \mathrm{L}$ normal saline was injected. For the 24 -h infection model group $(\mathrm{N}=10)$, after $50 \mu \mathrm{L}$ cerebrospinal fluid was taken out from the rat brain cistern, $50 \mu \mathrm{L}$ S. pneumoniae suspension $\left(10^{8} \mathrm{cfu} / \mathrm{mL}\right)$ was injected. After a natural disease course, the cerebrospinal fluid was collected for bacterial culture and white blood cell count at $24 \mathrm{~h}$ following injection, and the rats were killed, perfused, and sampled. For the 48-h infection model group $(\mathrm{N}=10)$, after $50 \mu \mathrm{L}$ cerebrospinal fluid was taken out from the rat brain cistern, $50 \mu \mathrm{L}$ S. pneumoniae suspension $\left(10^{8} \mathrm{cfu} / \mathrm{mL}\right)$ was injected. After a natural disease course, the cerebrospinal fluid was taken for bacterial culture and white blood cell count at $24 \mathrm{~h}$ following injection. At $48 \mathrm{~h}$ following injection, the rats were killed, perfused, and sampled. For the 5 day-infection model group $(\mathrm{N}=10)$, after $50 \mu \mathrm{L}$ cerebrospinal fluid was taken out from the rat brain cistern, 50 $\mu \mathrm{L} S$. pneumoniae suspension $\left(10^{8} \mathrm{cfu} / \mathrm{mL}\right)$ was injected. After a natural disease course, the cerebrospinal fluid was taken for bacterial culture and white blood cell count at $24 \mathrm{~h}$ following injection. At $48 \mathrm{~h}$ following injection, the rats were killed, perfused, and sampled.

\section{Perfusion and sampling}

Live rats were anesthetized with $0.15-0.3 \mathrm{~mL} / 100 \mathrm{~g} 10 \%$ chloral hydrate by intraperi- 
toneal injection and fixed onto the stereotaxic apparatus (abdomen up). Ribs were quickly cut open to allow exposure to heat. The left ventricular apex was intubated and the right auricula dextra was cut open, and $0.9 \%$ normal saline was dripped into the ventricular apex cannula until the outflow was basically colorless (the blood that flowed from the auricula dextra). Subsequently, perfusion was conducted with $4 \%$ paraformaldehyde fixation fluid. At this time, the rats would be convulsed (4 limbs and tail trembled). Perfusion was conducted again for $40 \mathrm{~min}$ until the rat bodies were stiff. Brain tissues were stripped off, soaked in $4 \%$ paraformaldehyde, and fixed for $24 \mathrm{~h}$ at $4^{\circ} \mathrm{C}$.

\section{Immunohistochemistry}

Brain tissues were conventionally dehydrated, soaked in paraffin wax, embedded, and sectioned, and brain slices containing the hippocampus and pallium were selected. A 5- $\mu \mathrm{m}$ thick slice was selected from 5 slices, adhered onto the lysine-pretreated slide, and dried. The rabbit hypersensitivity 2-step method was used to conduct immunohistochemical staining (Reference to kit instructions, Beijing Zhongshan Jinqiao Biological Technology Co., Ltd.). Rabbit anti-rat polyclonal NT-4/5 antibody (Millipore) was used at a working concentration of 1:500, and it was diluted in PBS at $4^{\circ} \mathrm{C}$. The first antibody was replaced with PBS as the negative control. For immunohistochemical staining, brown granules in the cytoplasm and nucleus were considered to be NT-4/5-positive granules. In addition, 10 representative highmagnification visual fields were selected in the corresponding areas of the pallium and hippocampus from each slice. Image scanning analysis was conducted using a computer image analysis system to measure the percentage of positive area in each visual field. The mean value of 10 visual fields was determined for each slice and compared.

\section{Statistical analysis}

The SPSS11.5 statistical software was used for data processing and data are reported as means \pm standard deviation; this was followed by randomized block variance analysis. The inspection level was set as $\alpha=0.05$, and $\mathrm{P}<0.05$ was considered to be a significant difference.

\section{RESULTS}

\section{Rat nerve function defect score}

After $24 \mathrm{~h}$ of infection, the rats presented obvious symptoms, including bad spirit, apastia, drowsiness, slow response, terrified nature, ataxia, and occasional hemiplegia. Severe cases presented non-rising body temperature or unobvious temperature increase and muzziness, accompanied with systemic hyperspasmia. In the 24-h infection group, 3 rats died, and 4 and 3 rats died in 48-h and 5-day infection groups, respectively. After a natural disease course, the symptoms of survived rats were relieved. In the normal control group, no rats died. In the 24-h infection group, the rat nerve function defect score was $2.91 \pm 0.55$. After a natural disease course, the symptoms of the survived rats were relieved. In the 48-h infection group, the rat nerve function defect score was $2.87 \pm 0.63$, and the symptoms of survived rats were relieved after a natural disease course. Between these 2 groups, no significant difference was 
noted. In the 5-day infection group, the rat nerve function defect score was $1.09 \pm 0.54$, which was significantly lower than that of the $24-\mathrm{h}$ infection group $(\mathrm{P}<0.05)$. In the normal control group, rats had no obvious symptoms at $24 \mathrm{~h}$ after $0.9 \%$ normal saline was injected into the rat brain cistern, and the rat nerve function defect score was zero. In the 24-h infection group, the white blood cell count of the cerebrospinal fluid was $3981.23 \pm 640.52 \times 10^{6} / \mathrm{L}$, which is significantly higher than $49.15 \pm 7.5 \times 10^{6} / \mathrm{L}$ before infection $(\mathrm{P}<0.05)$, and neutrophil granulocyte was predominant $(0.75-0.90 \%)$. Before infection, no bacterium grew in cerebrospinal fluid culture. After infection, we observed the growth of $S$. pneumoniae cells.

\section{Histopathology}

The infected brain tissues presented congestion and edema, and the brain parenchyma showed petechial hemorrhage. Hematoxylin and eosin staining showed cavum subarachnoidale, encephalocele, cerebral pia mater, exudation of neutrophil granulocytes and macrophages into the brain parenchyma, and fibrin exudation, as well as hemorrhagic necrosis foci (Figure 1A).

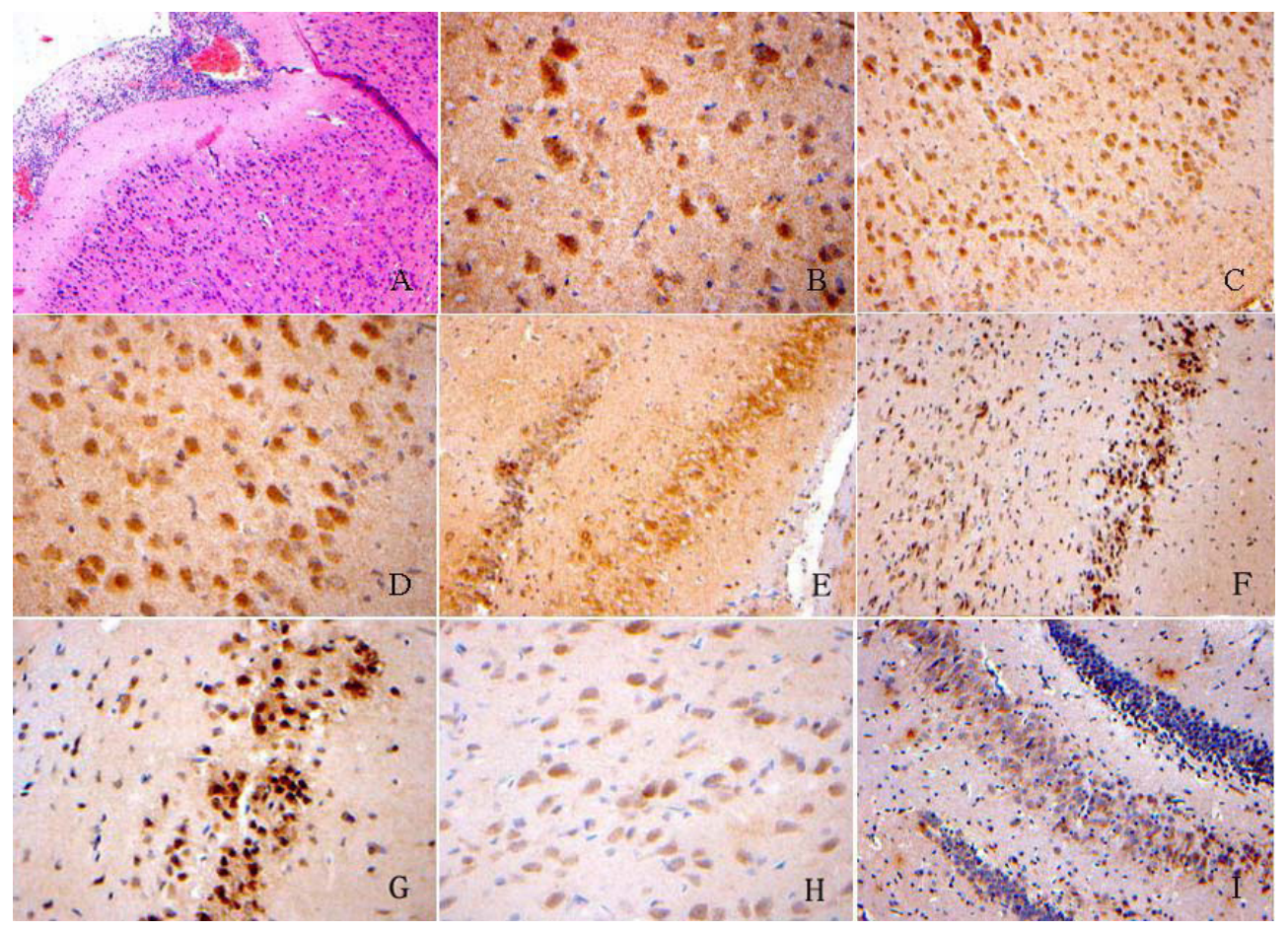

Figure 1. HE staining and NT-4/5 protein expression in brain tissue. A. Rat meninges HE staining of the meningitis model group at $24 \mathrm{~h}(100 \mathrm{X})$. B. NT-4/5 protein expression in pallium of the control group (400X). C. NT-4/5 protein expression in pallium of the 24-h infection group (200X). D. NT-4/5 protein expression in pallium of the 48-h infection group (400X). E. NT-4/5 protein expression in hippocampus of the control group (200X). F. NT-4/5 protein expression in hippocampus of the 24-h infection group (200X). G. NT-4/5 protein expression in hippocampus of the 48 -h infection group (400X). H. NT-4/5 protein expression in pallium the 5-day infection group (400X). I. NT-4/5 protein expression in hippocampus of the 5-day infection (200X). 


\section{NT-4/5 expression in rat pallium and hippocampus}

Table 1 shows that when compared with the normal control group, NT-4/5 expression in the rat pallium of the 24-h infection group significantly increased $(\mathrm{P}<0.05)$ (Figure 1B and C), without a significant difference between the 48-h and 24-h infection groups $(\mathrm{P}>0.05)$ (Figure 1C and D). Compared with the normal control group, NT-4/5 expression in the rat hippocampus of the 24-h infection group significantly increased $(\mathrm{P}<0.05)$ (Figure 1E and F), and there was no significant difference between the 48-h and 24-h infection groups $(\mathrm{P}>0.05)$ (Figure 1F and G). Irrespective of the pallium or hippocampus, NT-4/5 expression in the 5-day infection group was lower than that in the 24-h infection group $(\mathrm{P}<0.05)$ (Figure $1 \mathrm{C}, \mathrm{F}, \mathrm{H}, \mathrm{I})$, but both were significantly higher than that of the normal control group $(\mathrm{P}<0.05)$ (Figure 1B, E, H, I). In the negative control group, no positively stained granule was observed.

Table 1. NT-4/5 expressions in pallium and hippocampus with Streptococcus pneumonia meningitis.

\begin{tabular}{llc}
\hline Groups & \multicolumn{1}{c}{ Pallium } & Hippocampus \\
\hline Control group $(\mathrm{N}=10)$ & $0.0519 \pm 0.01462$ & $0.0587 \pm 0.0056$ \\
24-h infection group $(\mathrm{N}=7)$ & $0.1039 \pm 0.00831^{+\# *}$ & $0.1049 \pm 0.0109^{+\# *}$ \\
48-h infection group $(\mathrm{N}=6)$ & $0.1010 \pm 0.0090^{+}$ & $0.1045 \pm 0.0102^{+}$ \\
5-day infection group $(\mathrm{N}=10)$ & $0.0811 \pm 0.0076^{+}$ & $0.0813 \pm 0.0071^{+}$ \\
\hline
\end{tabular}

Data are reported as means \pm SD. ${ }^{+} \mathrm{P}<0.05$ compared with the control group; ${ }^{*} \mathrm{P}<0.05$ compared with the 5 -day infection group. $* \mathrm{P}>0.05$ compared with the 48 -h infection group.

\section{DISCUSSION}

This study showed that in a rat model with $S$. pneumoniae meningitis, NT-4/5 protein expression in both pallium and hippocampus increase at $24 \mathrm{~h}$ following inoculation of S. pneumoniae. This indicates that NT-4/5 has a certain role in the onset process of $S$. pneumoniae meningitis. NT- $4 / 5$ protein increase in $S$. pneumoniae meningitis is possibly related to the following factors. In bacterial meningitis, $S$. pneumoniae and the toxic substances released by it cause brain tissue hypoxia and ischemia. It is confirmed that the NT-4/5 levels in different neural cells increase with the elevation of ischemic damage (Diab et al., 1997). After cerebral hypoxia and ischemia, the subtoxic-concentration of glutamic acid, NMDA, and KA can induce NT-4/5 expression and resist the neurotoxicity of high-concentration glutamic acid (Longa et al., 1989). NT-4/5 can enhance the ability of cells to prevent calcium exudation. In the culture system supplemented with NT-4/5, neurons have a very strong resistance to the toxicity generated by the calcium ionophore A23187, suggesting that NT-4/5 can enhance the neuronal resistance to calcium-mediated damage (van de Beek et al., 2006) and prevent ischemic injury (Dery and Hasbun, 2007). It was also found that large-area cerebral infarction occurs in mice in which the NT-4/5 receptor gene was knocked out, indicating that NT-4/5 can reduce the cerebral susceptibility to ischemic injury. In addition, NT-4/5 can promote the survival, growth, and differentiation of neurons, and protect the hippocampus and cortical neurons from excitatory toxins and metabolic injury (Moon et al., 2010).

Elevation in the expression of NT-4/5 is the body's defense reaction to bacterial invasion. During the course of $S$. pneumoniae meningitis, bacterial products stimulate neural cells and inflammatory cells to express cytokines and inflammatory factors. These inflammatory mediators play a role and influence each other to generate continuous inflammatory reac- 
tions after cerebrospinal fluid asepsis and to cause bacterial meningitis to generate chronic inflammation sequelae. Cell wall products released by bacteriolysis due to early application of antibiotics can aggravate the local inflammatory reactions and further injure the blood-brain barrier, and cause ischemia and hypoxia of the brain tissue at the corresponding sites, leading to the elevation of NT- $4 / 5$ levels (Diab et al., 1997). In addition, these inflammatory mediators can regulate the expression of the NT-4/5 protein and mRNA. IL-6 and LB4 can stimulate the upregulation of NT-4 mRNA in the pallium and granulocyte and the NT-4 protein in the pallium (Ip et al., 1992; März et al., 1999). Therefore, an inflammatory stimulus could promote NT-4 generation through nerve cells and immune cells of the central nervous system in case of bacterial meningitis, and thus, NT-4/5 can protect extensively injured neurons.

This study confirms that NT-4/5 expression in the pallium and hippocampus are plentiful in case of meningitis. In combination with the above-discussed promotion in NT-4/5 expression and neuronal differentiation, survival research results suggest that NT-4/5 plays an important role in brain parenchyma neurogenesis in case of meningitis. On the other hand, pallium and hippocampus express higher levels of NT-4/5 for maintaining their state of proliferation. This study confirms that NT-4/5 expression rises during the early disease course of meningitis and reduces with disease development, which further suggests that after meningitis, endogenous NT-4/5 secretion is limited, and the self-repair and self-protective functions of the central nervous system are limited, and that it is still impossible to reverse the damage caused by meningitis.

Therefore, NT-4/5 expression increases in the brain tissues of young rats with S. pneumoniae meningitis, and it is more obvious during the early disease course. Early supplementation with exogenous NT- $4 / 5$ or stimulating endogenous NT-4/5 expression by using multiple routes can not only directly nourish injured neurons, but can also promote neuronal differentiation and plasticity to protect nerve system. Our experimental results not only provide trial basis for clinically applying NT-4/5 gene to treat nervous system diseases, but also establish the scientific theory basis and experimental base for further expressing the NT-4/5 protein, for preparing monoclonal antibodies as well as for developing gene therapy for some diseases. New progresses are expected in the treatment of meningitis and other cerebral injuries, and these may help us overcome problems such as high mortality of nervous system-related diseases and the high incidence rate of the sequelae caused by neuronal regeneration.

\section{REFERENCES}

Chen Y, Yang R, Yao L, Sun Z, et al. (2007). Differential expression of neurotrophins in penises of streptozotocin-induced diabetic rats. J. Androl. 28: 306-312.

Chi MM and Powley TL (2007). NT-4-deficient mice lack sensitivity to meal-associated preabsorptive feedback from lipids. Am. J. Physiol. Regul. Integr. Comp. Physiol. 292: R2124-R2135.

Chung YJ, Farraj A, Coates NH, Gavett SH, et al. (2007). Increased neurotrophin production in a Penicillium chrysogenuminduced allergic asthma model in mice. J. Toxicol. Environ. Health A 70: 1020-1026.

Dery MA and Hasbun R (2007). Changing epidemiology of bacterial meningitis. Curr. Infect. Dis. Rep. 9: 301-307.

Diab A, Zhu J, Lindquist L, Wretlind B, et al. (1997). Haemophilus influenzae and Streptococcus pneumoniae induce different intracerebral mRNA cytokine patterns during the course of experimental bacterial meningitis. Clin. Exp. Immunol. 109: 233-241.

Engelhardt M, Di Cristo G, Berardi N, Maffei L, et al. (2007). Differential effects of NT-4, NGF and BDNF on development of neurochemical architecture and cell size regulation in rat visual cortex during the critical period. Eur. J. Neurosci. 25: 529-540.

Fandl JP, Tobkes NJ, McDonald NQ, Hendrickson WA, et al. (1994). Characterization and crystallization of recombinant 
human neurotrophin-4. J. Biol. Chem. 269: 755-759.

Golz G, Uhlmann L, Ludecke D, Markgraf N, et al. (2006). The cytokine/neurotrophin axis in peripheral axon outgrowth. Eur. J. Neurosci. 24: 2721-2730.

Hefti F (1997). Pharmacology of neurotrophic factors. Annu. Rev. Pharmacol. Toxicol. 37: 239-267.

Ip NY, Ibáñez CF, Nye SH, McClain J, et al. (1992). Mammalian neurotrophin-4: structure, chromosomal localization, tissue distribution, and receptor specificity. Proc. Natl. Acad. Sci. U. S. A. 89: 3060-3064.

Jabbar S, Harada F, Aita M, Ohishi M, et al. (2007). Involvement of neurotrophin-4/5 in regeneration of the periodontal Ruffini endings at the early stage. J. Comp. Neurol. 501: 400-412.

Longa EZ, Weinstein PR, Carlson S and Cummins R (1989). Reversible middle cerebral artery occlusion without craniectomy in rats. Stroke 20: 84-91.

Malamitsi-Puchner A, Nikolaou KE, Economou E, Boutsikou M, et al. (2007). Intrauterine growth restriction and circulating neurotrophin levels at term. Early Hum. Dev. 83: 465-469.

März P, Heese K, Dimitriades-Schmutz B, Rose-John S, et al. (1999). Role of interleukin-6 and soluble IL-6 receptor in region-specific induction of astrocytic differentiation and neurotrophin expression. Glia 26: 191-200.

Moon SY, Chung DR, Kim SW, Chang HH, et al. (2010). Changing etiology of community-acquired bacterial meningitis in adults: a nationwide multicenter study in Korea. Eur. J. Clin. Microbiol. Infect. Dis. 29: 793-800.

Nakajima K, Tohyama Y, Maeda S, Kohsaka S, et al. (2007). Neuronal regulation by which microglia enhance the production of neurotrophic factors for GABAergic, catecholaminergic, and cholinergic neurons. Neurochem. Int. 50: 807-820.

Nikolaou KE, Malamitsi-Puchner A, Boutsikou T, Economou E, et al. (2006). The varying patterns of neurotrophin changes in the perinatal period. Ann. N. Y. Acad. Sci. 1092: 426-433.

Thoenen H (1995). Neurotrophins and neuronal plasticity. Science 270: 593-598.

van de Beek D, de Gans J, Tunkel AR and Wijdicks EF (2006). Community-acquired bacterial meningitis in adults. $N$. Engl. J. Med. 354: 44-53.

Xie CW, Sayah D, Chen QS, Wei WZ, et al. (2000). Deficient long-term memory and long-lasting long-term potentiation in mice with a targeted deletion of neurotrophin-4 gene. Proc. Natl. Acad. Sci. U. S. A. 97: 8116-8121.

Yin Q, Kemp GJ, Yu LG, Wagstaff SC, et al. (2001). Neurotrophin-4 delivered by fibrin glue promotes peripheral nerve regeneration. Muscle Nerve 24: 345-351. 